\title{
2 - Força e fraqueza do capitalismo industrial no Brasil
}

\author{
Marcio Pochmann
}

SciELO Books / SciELO Livros / SciELO Libros

POCHMANN, M. Força e fraqueza do capitalismo industrial no Brasil. In: Brasil sem industrialização: a herança renunciada [online]. Ponta Grossa: Editora UEPG, 2016, pp. 66-104. ISBN 978-85-7798-216-5. Available from SciELO Books $<$ http://books.scielo.org $>$.

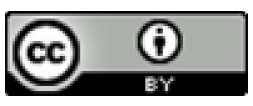

All the contents of this work, except where otherwise noted, is licensed under a Creative Commons Attribution 4.0 International license.

Todo o conteúdo deste trabalho, exceto quando houver ressalva, é publicado sob a licença Creative Commons Atribição 4.0.

Todo el contenido de esta obra, excepto donde se indique lo contrario, está bajo licencia de la licencia $\underline{\text { Creative }}$ Commons Reconocimento 4.0. 

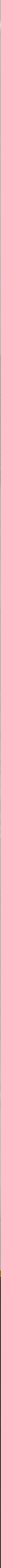

Força e fraqueza do capitalismo industrial no Brasil 
Nesta parte que trata do tema do capitalismo industrial brasileiro, registram-se duas ordens distintas e complementares de narrativas. A primeira voltada ao entendimento das condições que propiciaram a passagem da antiga sociedade agrária à urbana e industrial no país durante a primeira metade do século XX.

Para isso, a referência principal de abordagem assenta-se no período histórico que demarcou o conjunto de especificidades resultantes da constituição prévia do capitalismo no país de passado colonial e submetida à economia primário exportadora. Ao mesmo tempo, a consideração necessária a respeito da fase pela qual o capitalismo internacional monopolista vigia preponderantemente e responsável que foi pelas condicionalidades e determinações próprias impostas ao desenvolvimento do padrão de industrialização tardia.

Destaca-se, assim, que a hegemonia inglesa exercida ao longo do século XIX e até a primeira Guerra Mundial (1914 - 1918) terminou por impactar parcela importante da trajetória de formação do capitalismo brasileiro. Isso pode ser observado tanto na forma de rompimento com o antigo pacto colonial como no surgimento do Estado Nacional no Brasil.

Nesse sentido, constatam-se também os traços da pressão inglesa associada ao fim do tráfico negreiro e à referência internacional do padrão monetário ouro-libra com a difusão do crédito voltado ao financiamento do ciclo ferroviário. Tudo isso durante a passagem da 
economia nacional mercantil escravista (1822 a 1888) para a economia capitalista primária exportadora (1889 - 1930).

A constituição prévia do capital mercantil e da divisão social do trabalho foi necessária para a ascensão do modo dominante de produção capitalista no Brasil. A partir daí, a constituição do capital industrial encontrou caminho para o seu fortalecimento até deixar de estar subordinado à dinâmica da economia primária exportadora vigente até a década de 1920.

No período histórico de praticamente meio século, compreendido entre as décadas de 1880 e 1920, as bases pelas quais a economia capitalista exportadora transitou para a industrialização foram estabelecidas concomitantes com a crise da hegemonia inglesa. Por outro lapso de tempo equivalente a cinco décadas, mais precisamente entre os anos de 1930 e 1980, o Brasil perseguiu o padrão de industrialização tardia no rastro do exercício capitalista decorrente da hegemonia estadunidense.

Neste contexto que emerge a segunda preocupação analítica no âmbito da industrialização brasileira. Toma-se como referência não apenas a trajetória do desenvolvimento da industrialização nacional, mas também a crise iniciada na década de 1980 e que descortinou, em consequência, o movimento maior da desindustrialização.

Durante o ciclo da industrialização brasileira, entre as décadas de 1930 e 1980, encontram-se dois movimentos distintos. Inicialmente aquele em que predominou o estabelecimento e avanço da industrialização restringida durante os anos de 1930 a 1955. Nesse período, a industrialização transcorreu sem a plena constituição do setor dos meios de produção, o que concedeu primazia ao saldo do comércio externo enquanto mecanismo de financiamento das importações de máquinas e equipamentos industriais. 
Não obstante o movimento endógeno da acumulação de capital ser determinado pela expansão industrial, constatou-se a estabilidade do progresso tecnológico e os avanços movidos no parque produtivo fundamentalmente por imediata demanda interna. O perfil de crescimento horizontal da produção industrial revelou os limites da autodeterminação da acumulação capitalista sem a presença do setor de bens de produção.

Isso somente viria a ser superado a partir da adoção de grandes blocos de investimentos capazes de implantar uma nova capacidade produtiva que potencializou a expansão nos setores de bens de consumo duráveis e de capitais bem adiante da determinação da demanda imediata. Por meio da industrialização pesada que a autodeterminação do desenvolvimento industrial se consolidou no Brasil.

Para isso, três grandes blocos de investimentos se fizeram essenciais. O primeiro se deu ainda na fase da industrialização restringida, com a instalação das indústrias de base como a Companhia Siderúrgica Nacional (CSN, em 1941), a Vale do Rio Doce (em 1942), a Álcalis (em 1943), a Fábrica Nacional de Motores (em 1943), a Hidrelétrica do São Francisco (em 1945) e a Petrobrás (em 1953).

O segundo bloco de investimentos transcorreu nos anos de 1950, com a implantação do Plano de Metas (1956-60) e o terceiro, na década de 1970, com estabelecimento do segundo Plano Nacional de Desenvolvimento (1976-80). A prevalência da industrialização pesada concentrou-se entre os anos de 1955 a 1980, quando o centro do capitalismo mundial localizava-se nos Estados Unidos e caracterizava-se pelo cumprimento do acordo de Bretton Woods vigente entre as décadas de 1940 e 1970 e sob o predomínio da Guerra Fria (1947 - 1991). 
Gráfico 01 - Evolução média anual da renda por habitante no Brasil e no mundo (em \%)

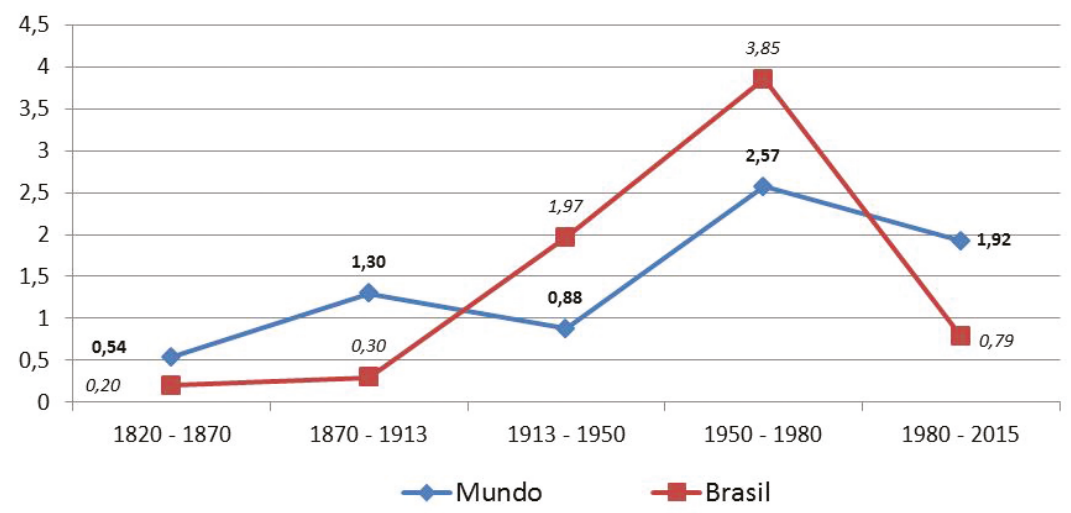

Fonte: Maddison, 2011 ; IBGE - Censos demográficos e Pnad's (elaboração própria).

Ainda no âmbito desta segunda preocupação analítica ressalta-se a significativa inflexão na trajetória de dominação do capital industrial sobre as forças produtivas. Isso porque a partir da década de 1980, alguns sinais do processo de desindustrialização no Brasil começaram a ser percebidos, concomitante com a desaceleração rápida do PIB por habitante.

Nos últimos 35 anos, que compreende o período de 1981 a 2015, o capitalismo brasileiro apresentou trajetória próxima à semiestagnação do rendimento por habitante. Após ter registrado crescimento mais acelerado do PIB per capita que o conjunto do mundo entre os anos de 1913 a 1980, o país voltou a deter desempenho inferior aos demais países, conforme verificado no período de 1820 a 1913, que compreendeu o regime do Império (1822 - 1989) e parte da República Velha (1889 - 1930).

A partir da década de 1980, o predomínio da dominância financeira associado ao constrangimento interno que decorreu da 
valorização cambial terminou por subordinar o capital industrial, apequenando o papel da burguesia manufatureira e tornando cada vez mais acanhada a indústria de transformação brasileira. Seja qual for o indicador considerado, a indústria perdeu participação relativa tanto na produção como na ocupação total, enquanto aumentou o seu peso nas importações totais.

Ao contrário do ciclo da industrialização tardia, quando o papel do setor público se mostrou fundamental para a constituição de rápida expansão capitalista no Brasil, assistiu-se, a partir das duas últimas décadas do século XX, o funcionamento do Estado mais associado aos interesses da financeirização de riqueza e do agronegócio. Da elevação da carga tributária à privatização de parcela do setor produtivo estatal, predominou, em geral, a lógica da desindustrialização assentada na condução da política econômica de altas taxas de juros e de valorização cambial.

Também contribuiu para desfazer o ciclo da industrialização tardia, a mudança na atuação dos Estados Unidos enquanto centro dinâmico do capitalismo mundial. O abandono das regras monetárias e financeiras do acordo de Bretton Woods (1944 - 1973) e o fim da Guerra Fria abriram nova fronteira tanto para a expansão geográfica da manufatura como para crescente valorização financeira do capital.

Isso porque a opção estadunidense pelo conjunto de políticas neoliberais adotadas a partir da década de 1980 conduziu à globalização financeira que trouxe como consequência a difusão de políticas liberalizantes no interior dos demais países. O esvaziamento da capacidade dos Estados Nacionais impulsionar autonomamente suas políticas econômicas, como, por exemplo, a monetária, se fez perceber rapidamente pelo poder crescente do Banco Central dos Estados Unidos (FED). 
Da mesma forma, o avanço do processo de concentração do poder de controle da produção e distribuição pelas grandes corporações transnacionais, através das cadeias globais de valor, enfraqueceu a presença da indústria no ocidente, em geral, vis à vis o deslocamento da manufatura para a Ásia, sobretudo a China. A contrapartida ao apequenamento do capital industrial no Brasil foi o engrandecimento da financeirização e o retorno do capital comercial vinculado à exportação de produtos primários intensivos em recursos humanos e naturais, tendo o baixo dinamismo econômico nacional como resultado principal.

Diante disso, interessa expressar enquanto referência do capítulo, o critério adotado pela análise desenvolvida em função de dois distintos eixos de abordagens. Por um lado, o monitoramento analítico do desenvolvimento e crise do padrão de industrialização tardia no Brasil a partir dos determinantes de natureza interna do país e, por outro lado, as repercussões dos determinantes de natureza externa no contexto nacional.

\section{Crescimento industrial sem industrialização (pré-1930)}

A industrialização no Brasil foi produto de verdadeira luta histórica por sua implantação. Ela não ocorreu espontaneamente, mas por apoio político e econômico de significativa expressão do sentimento nacional.

Como se sabe, a instalação das primeiras fábricas de manufatura foi autorizada somente com a vinda da família Real, em 1808. Até 
então, a criação de indústrias era proibida por D. Maria I desde 1785, salvo as fábricas de panos grossos para uso de escravos.

Com D. João VI, a abertura dos portos ao comércio externo foi acompanhada por taxa de $24 \%$ sobre produtos importados, geralmente de manufaturados, ainda que para Inglaterra fosse de $15 \%$. Mas isso se mostrou insuficiente para implementar a industrialização nacional.

Em pleno século XIX, a presença de algum tipo de investimento industrial e a criação de indústrias, geralmente na produção de sabão, velas, fiação, tecelagem, alimentos, chapéus, calçados, serrarias, vidros, óleo, entre outras, eram isoladas e operavam com misto de escravos e trabalhadores livres. Somente com o avanço da acumulação de capital oriundo do ciclo cafeeiro que o Brasil pode contar com importante crescimento na quantidade de indústrias, especialmente na região Sudeste que em 1881 registrou 29 fábricas têxteis das 46 existentes em todo o país (SZMRECSÁNY; AMARAL, 2002; GRAÇA FILHO, 2004).

$\mathrm{Na}$ transição da economia mercantil nacional fundada no trabalho escravo entre as décadas de 1820 a 1870 para a economia capitalista exportadora que o capital industrial surgiu e se expandiu subordinado ao capital cafeeiro. A década de 1880, por exemplo, pode ser identificada como aquela em que a formação do capital industrial apresentou rápida e significativa aceleração, concomitantemente com o auge do ciclo de exportação do café (AURELIANO, 1981; CANO, 1977; MELLO, 1975; SILVA, 1976).

Em plena manifestação da longa Depressão (1873 a 1896) que atingiu, sobretudo, a Inglaterra e coincidiu ainda com o florescimento da segunda Revolução Industrial, o capital industrial ganhou alguma expressão no Brasil. Naquele momento, o sistema de concorrência 
capitalista se transformava cada vez mais a livre competição em monopolização das estruturas de mercado.

Com as alterações liberais consagradas na segunda metade do século XIX, por meio da lei das terras, do direito de propriedade e da abolição do trabalho escravo, o Brasil foi gradualmente transitando para a economia capitalista. Enquanto isso proliferou o centro dinâmico mundial situado na Inglaterra, por meio de sua forte armada militar, do padrão ouro-libra e da liderança na exportação de bens industriais.

Para o Brasil, a transição para o capitalismo representou a continuidade do modelo primário exportador. Na Divisão Internacional do Trabalho em que o Brasil se situou enquanto importador de bens industriais e exportador de produtos primários, o financiamento era prioritariamente viabilizado pela Inglaterra.

A prevalência do padrão monetário internacional ouro-libra condicionou o Brasil às exigências da hegemonia inglesa, sobretudo com o movimento do grande capital financeiro europeu em busca de novos mercados no mundo. A defesa do livre cambismo era acompanhada pela ordem dos fluxos de capitais sem controle e em plena existência do Estado Mínimo, cujas funções principais eram o exercício do monopólio da tributação, da emissão monetária e das forças armadas.

Neste contexto que a política imperialista no século XIX compreendia a expansão e dominação territorial colonialista. Em pleno auge, o Império Britânico chegou a dominar $1 / 4$ da população e do território do planeta, utilizando-se tanto da ocupação militar mais acentuada na África e Ásia como do comércio e poder financeiro na América Latina.

Com a Grande Depressão entre 1873 e 1896, o imperialismo inglês registrou importante impulso na demanda de novos mercados, fontes de matérias-primas e aplicação do excesso de capital existente na Europa. As 
exportações de capitais para a América Latina e, em grande medida, o Brasil contribuíram para tornar mais dependentes suas economias, especializadas na produção e exportação de produtos primários e importadores de bens industrializados e de capitais na forma de empréstimos para a construção de ferrovias, serviços públicos, telégrafos, entre outros.

Por outro lado, a continuidade da prevalência das exportações de bens primários levou à mudança no eixo econômico brasileiro. Isso porque coube ao estado de São Paulo liderar o centro de dinamismo nacional por meio do complexo cafeeiro constituído pela produção e processamento do café, do sistema de transporte (portos, estradas e ferrovias), do comércio interno, dos serviços bancários e do uso abundante de mão de obra.

Em certo sentido, a ascensão da aristocracia cafeeira paulista se mostrou possível conjuntamente com o maior peso relativo da província de São Paulo na economia e política nacional na vigência da República Velha (1889 a 1930). Até a década de 1930, o predomínio liberal da República Velha, com a centralidade do Estado mínimo, não deixou de atender aos interesses dominantes da economia capitalista cafeeira.

O Estado Republicano contribuiu tanto para o apoio à imigração de mão de obra livre não africana como para a política de valorização do café, sobretudo a partir do "Acordo de Taubaté", em 1906. Com a sustentação da economia de exportação, a indústria cresceu em quantidade, indicando haver mais convergência do que contradição entre os capitais cafeeiro e industrial.

No ano de 1889, por exemplo, o Brasil contabilizava a presença de 630 estabelecimentos industriais que empregavam menos de 25 mil operários. Deste universo, 2/3 haviam surgidas na década de 1880, conforme permite observar o Gráfico 02. 
Gráfico 02 - Brasil: quantidade de indústrias e de operários conforme o período de fundação da empresa em 1889

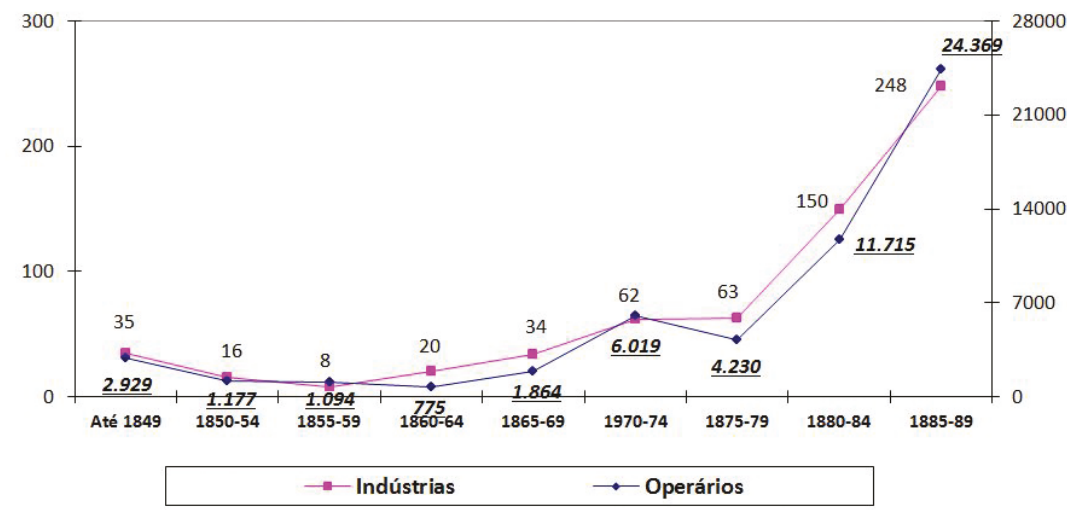

Fonte: IBGE (elaboração própria).

Trinta anos depois, em 1920, o país contava com quase 13,6 mil indústrias, com 294 mil operários. Entre os anos de 1889 e 1920, o número de indústrias foi multiplicado por 21,3 vezes, enquanto a quantidade de operários aumentou acumuladamente 442,1\%.

O crescimento das indústrias esteve diretamente associado à relação subordinada e extensiva do capital industrial ao capital cafeeiro, respondendo, em parte, pela demanda proveniente do mercado interno ampliado pelo assalariamento. Das atividades do complexo exportador de café, cuja determinação era estabelecida pela demanda externa, transcorriam transbordamentos de capital cafeeiro para indústria, sobretudo nas fases de expansão das exportações.

Isso parece inegável, quando se nota que a trajetória das receitas obtidas pelas exportações é seguida, no mesmo sentido, pelos investimentos industriais, segundo o Gráfico 03. Pelo menos é o que se verifica até a década de 1920, uma vez que a partir da Grande Depressão de 1929, o investimento cresce, deslocando-se da queda das receitas de exportações. 
Nas fases de baixa das receitas de exportação, quando também o investimento industrial era afetado negativamente, a produção de manufatura tendia a crescer à medida que aumentava a proteção ao mercado interno, especialmente com a desvalorização cambial e dificuldades de importação. As exportações de café representavam 2/3 do comércio externo brasileiro.

Gráfico 03 - Brasil: evolução do índice de investimento industrial e das receitas de exportação $(1865 / 68=100)$

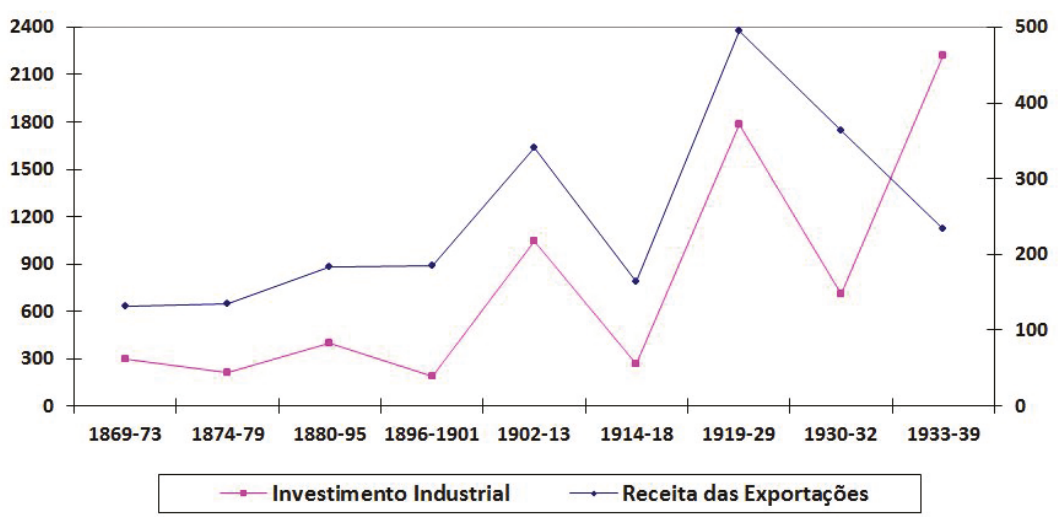

Fonte: Suzigan (1986) (elaboração própria).

Com isso a expansão da burguesia industrial enquanto fração constitutiva da classe dominante na economia capitalista de exportação revelava sua forte conexão originária com os proprietários cafeicultores (MELLO, 1982), bem como em menor participação inicial dos comerciantes imigrantes de importação e exportação (DEAN, 1976, BRESSER-PEREIRA, 1981). Isso porque, pela economia cafeeira, a mão de obra assalariada se incorporou à produção, o mercado interno se fortaleceu e a burguesia concentrou uma massa de capital promotora da grande indústria capitalista. 
No final do século XIX, a regulamentação da Bolsa de Valores (Decreto de 1897), associada ao Código Comercial de 1850 e os estímulos creditícios favoreceram a concentração de capital e a expansão dos industriais. Ademais de ser matriz da expansão da burguesia industrial, a economia cafeeira fez de São Paulo o lócus do território nacional consolidador da expansão da manufatura.

Assim, o vigor da economia capitalista a partir do seu principal centro dinâmico no estado de São Paulo terminou por dominar o crescimento das industriais. No ano de 1919, por exemplo, o estado paulista respondia por quase $1 / 3$ do total do Valor da Transformação Industrial (VTI), enquanto em 1907 era de 16\%, o que correspondeu ao crescimento acumulado de $98,1 \%$.

Para o mesmo período de tempo, a província do Rio de Janeiro (atualmente congregando a Guanabara e Rio de Janeiro) decresceu sua participação relativa no VTI em 25,4\%, passando de 37,8\% (1907) para 28,2\% (1919). As províncias do Rio Grande do Sul e de Pernambuco também diminuíram seus pesos relativos no VTI em 17,8\% e 8,1\%, respectivamente, entre os anos de 1907 e 1919.

Mas para haver sequência no processo de expansão do capital industrial liderado pelo café no interior da economia capitalista de exportação, algumas condições prévias foram necessariamente fundamentais. A começar pela existência de uma economia mercantil.

Desde a década de 1880, o salto na acumulação de capital pelo setor exportador de café decorreu de uma exitosa combinação. De um lado, a introdução de novos métodos de beneficiamento do café, que permitiu elevar a sua qualidade, bem como o avanço na construção do sistema de transporte ferroviário que reduziu custos e distâncias no deslocamento da produção para exportação. 
Gráfico 04 - Brasil: evolução da quantidade de imigrantes africanos e não africanos que desembarcaram em anos selecionados (em mil)

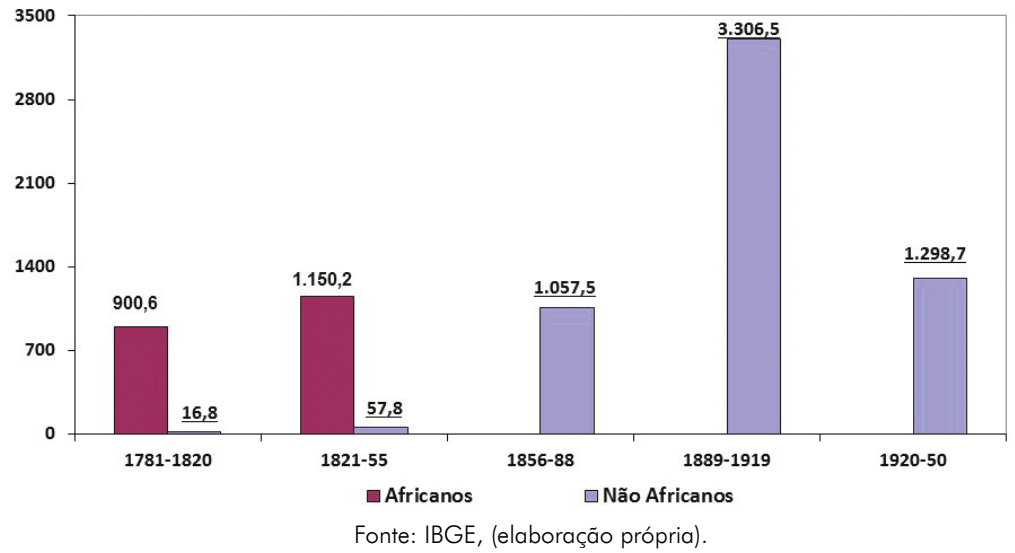

De outro lado, o aumento significativo da mão de obra assalariada em substituição ao trabalho escravo. Em 1888, com a proibição da escravidão, o capitalismo se fundamentou pela ampliação da divisão social do trabalho.

Na década de 1850, com a proibição do tráfego de escravos, o desembarque de africanos nos portos brasileiros praticamente desapareceu. Entre 1781 e 1855, por exemplo, ingressaram mais de 1,5 milhão de escravos.

Desde a segunda metade do século XIX que o desembarque de mão de obra livre no Brasil passou a crescer significativamente. Se entre 1781 e 1855, somente 75 mil não africanos ingressaram no Brasil, nos anos de 1856 a 1888 - antes ainda da abolição da escravatura -, mais de 1 milhão de imigrantes não africanos ingressaram no país. 
Mas foi a partir de 1889 que a quantidade de ingressantes na condição de mão de obra livre saltou rápida e significativamente. De 1889 a 1919, por exemplo, mais de 3,3 milhões de não africanos desembarcam no Brasil.

Em meio à abundância de mão de obra que caracterizou a constituição do mercado de trabalho no Brasil, notou-se que o crescimento industrial subordinado à expansão do setor cafeeiro de exportação não se mostrou suficiente para permitir que os ganhos de produtividade fossem compartilhados com os operários. Entre 1914 e 1920, por exemplo, o aumento real acumulado pela produção industrial foi de $88 \%$, ao passo que os salários registraram redução de 10,4\% no seu poder aquisitivo.

A alta taxa de lucratividade nas indústrias não resultou apenas no rebaixamento dos salários reais, em grande medida derivada do excedente de mão de obra imigrante e nacional. Contribuiu para isso, também, a política tributária de proteção à indústria e de rebaixamento tarifário à importação de bens de capitais.

Gráfico 05 - Brasil: evolução do índice de inflação, do salário e da produção industrial entre 1914 e 1920 (1914 = 100)

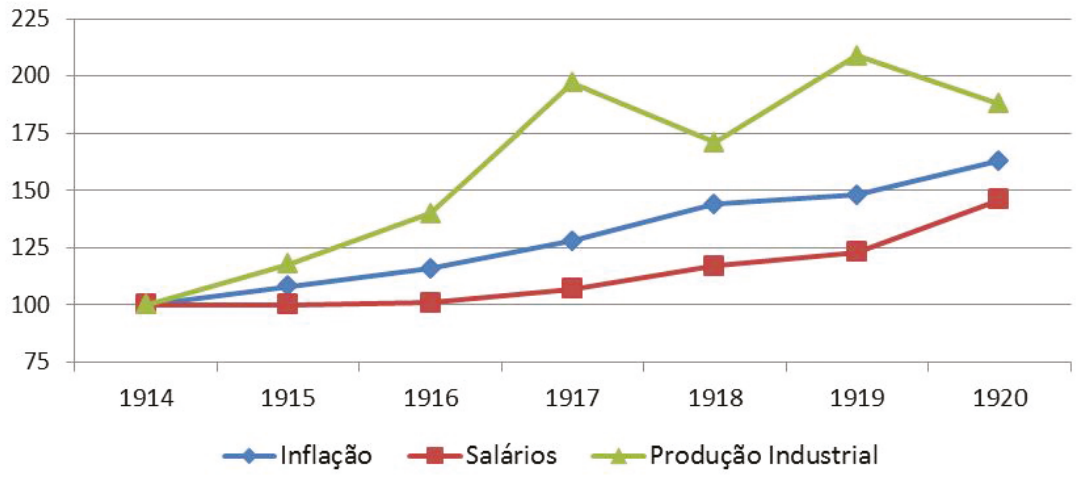


De todo o modo, a indústria que cresceu foi a produtora de bens leves de consumo assalariado (alimentos e vestuário). O deslocamento da força de trabalho para as cidades apontou os primeiros sinais do novo rumo de transição da antiga sociedade agrária para sociedade urbana e industrial.

A partir da década de 1930 surge outra fase do desenvolvimento nacional, com a dinâmica industrial cada vez mais liberada da outrora subordinação à economia cafeeira. Assim, à demanda externa que movia o complexo exportador e, este, por sua vez, fomentava o crescimento industrial registrado entre as décadas de 1880 e 1920, passou a ser substituída pela demanda proveniente do mercado interno.

A industrialização que teve início no Brasil transcorreu a partir daí tardiamente. Enquanto a indústria que ganhou impulso foi a de bens de consumo não duráveis, vários países na Europa e Estados Unidos encontram-se, à época, com o desenvolvimento industrial bem mais avançado.

\section{Ciclo da industrialização tardia (1930 -1980)}

Da constituição do capitalismo no último quartel do século XIX à instalação do processo de industrialização tardia, o Brasil aguardou mais de seis décadas de dominância do capital mercantil. Não obstante a existência do capital industrial entre as diversas formas de capital protagonizadas pela ascensão da economia capitalista exportadora (1890 - 1930), a sua presença era passiva e dependente.

Somente a partir dos anos de 1930 e, pelo menos até a década de 1980 que o capital industrial manteve-se ativo no contínuo processo central de revolucionar e liderar o conjunto das forças produtivas. Mas 
o processo de dominação do capital industrial esteve permeado por especificidades econômicas e políticas substanciais.

Do ponto de vista econômico, o ciclo da industrialização tardia se compôs de duas fases distintas, sendo a primeira restringida e a segunda pesada. A fase restringida da industrialização transcorreu no período entre as décadas de 1930 e 1950, quando o passado do Estado Mínimo e a política econômica do livre cambismo foram abandonados.

Com a mudança radical procedida no processo de acumulação de capital desde a adoção da política de defesa da renda e do emprego a partir da Grande Depressão de 1929, o Brasil recuperou, já em 1933, o mesmo nível da produção industrial registrado em 1928, chegando em 1938 com produto industrial 44\% superior ao de 1928. Nos Estados Unidos, por exemplo, o produto industrial do ano de 1933 foi $36 \%$ menor do verificado em 1928 e 28\% inferior em 1939, ao contrário da Rússia que não registrou queda no nível de atividade manufatureira na década de 1930, sendo superior ao ano de 1928 em 98\% em 1933 e de $377 \%$ em 1938.

A nova política de industrialização implementada no Brasil permitiu sair mais cedo da crise de 1929. Ao mesmo tempo, impulsionou o deslocamento do antigo centro dinâmico nacional assentado na produção e exportação de bens primários, especialmente decorrentes da economia cafeeira, para a produção de manufatura sob o comando dos investimentos autônomos, sobretudo puxados pelo Estado.

A partir de então, a força endógena do desenvolvimento da economia nacional tornou-se preponderante pela primeira vez no Brasil, esvaziando a importância do mercado externo na determinação da economia exportadora e, por consequência, da produção industrial. Mas para isso, a reorganização do Estado Nacional se mostrou estratégica, pois sem o controle dos macro preços da economia, como o 
câmbio, os juros, os tributos e o mercado de trabalho, a industrialização seguiria patinando.

Gráfico 06 - Evolução do índice do produto industrial no Brasil, Estados Unidos e Rússia de 1928 a $1938(1928=100)$

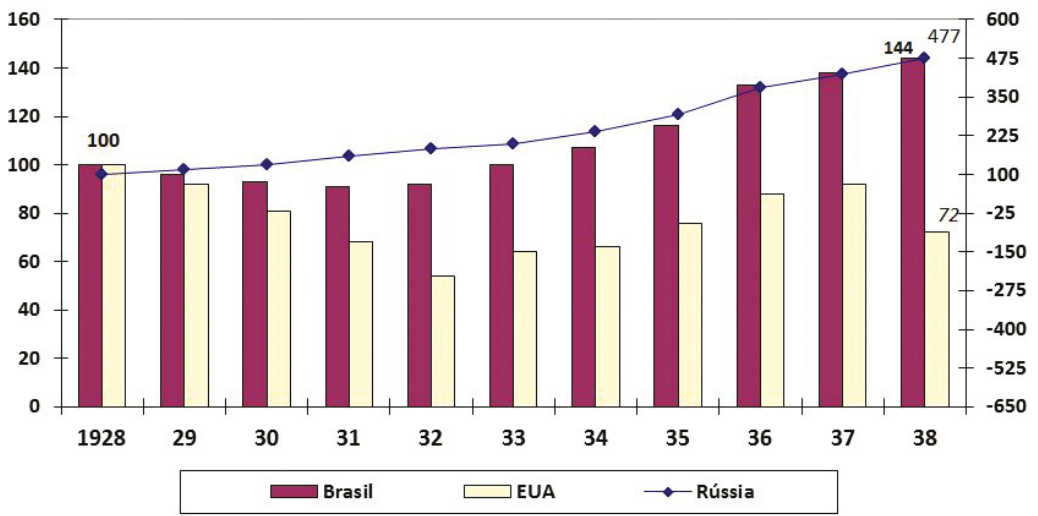

Fonte: Gazier (2009) (elaboração própria).

Mesmo assim, a capacidade do capital industrial subordinar os demais componentes das forças produtivas terminou não sendo plena. O fortalecimento da burguesia industrial, bem como a sua associação ao poder do Estado tornaram politicamente viável a reorientação da política econômica de intervenção em prol do desenvolvimento nacional.

A restrição maior à industrialização tardia no Brasil decorreu, pelo menos até a década de 1950, da ausência do setor de bens de capital. Para compensar, a exportação de bens primários seguiu sendo importante, capaz de financiar a necessária importação de máquinas e equipamentos para o desenvolvimento da industrialização nacional.

Neste sentido que a transição para a nova sociedade urbana e industrial não significou o rompimento com o velho agrarismo. Ao 
contrário oposição intrafrações da classe dominante, especialmente da burguesia industrial com a aristocracia cafeicultora, notou-se a presença de inter-relações diretas e indiretas ao longo do tempo.

Em grande media, a permanência da aliança política no interior dos capitalistas impossibilitou a realização de reformas clássicas do capitalismo contemporâneo, praticamente efetivadas nos países desenvolvidos. Assim, a emergência do capitalismo selvagem, distante de reformas como a fundiária, tributária e social, patrocinou estranha integração entre o moderno e o atrasado no Brasil.

Por força disso, a sequência da condição de antiga província de São Paulo, herdeira da economia capitalista primário-exportadora, transformou-se no centro dinâmico territorial da industrialização. Isso porque desde o final do século XIX que a economia paulista já predominava para além da economia cafeeira.

A expansão na quantidade de indústrias, como verificado entre os anos de 1911 a 1919, garantiu a São Paulo o crescimento médio anual de 7,5\% e de 6,6\% entre 1920 e 1928. No Brasil como um todo, o crescimento médio anual da indústria foi de $4,4 \%$ e de $4,5 \%$ para o mesmo período de tempo, respectivamente.

A construção do novo pela industrialização tornou-se mais difícil, por meio da desconstituição da economia cafeeira - como defendia o movimento político tenentista emergente desde a década de 1920 - poderia levar ao maior enfraquecimento do débil capitalismo brasileiro. Diante do alarmante endividamento dos cafeicultores, os bancos corriam o risco do colapso, o que ampliaria mais o desemprego e o rendimento das famílias, tornando ainda menor o mercado interno, com a quebra de indústrias e empresas dos serviços e comércio e o rebaixamento da arrecadação tributária do Estado. 
Dialeticamente, a salvação da economia cafeeira na crise de 1929 pelo novo governo liderado por Getúlio Vargas foi acompanhada pela crescente extração da renda exportadora por meio da política cambial de transferência às indústrias em expansão pelo mercado interno. Também a elevação da carga tributária, em cerca de 3\% do Produto Interno Bruto, e a ampliação da oferta de crédito compensaram as restrições da industrialização tardia por meio da importação de máquinas e equipamento industriais.

Da inédita adoção de políticas de natureza anticíclica à velha economia cafeeira no início da década de 1930, passando pelo fortalecimento da industrialização até a metade da década de 1950, a sustentação da renda interna mobilizou recursos para motivar o avanço das indústrias cada vez mais responsáveis pela dinâmica econômica. Ao mesmo tempo, o crescente poder de subordinar outras frações da classe dominante em torno da integração do mercado nacional pelo capital industrial centrado no estado de São Paulo.

No Brasil, a expansão média anual da indústria de transformação em 6,4\% entre 1928 e 1939 e em 7,8\% entre 1939 e 1949 foi acompanhada da redução do grau de abertura comercial de $28 \%$ para $6 \%$ do PIB entre 1930 e 1960. Para o mesmo período, o estado de São Paulo registrou, respectivamente, o crescimento médio anual da industrial de transformação de $7,3 \%$ e de $9,8 \%$, o que permitiu saltar da responsabilidade por quase $32 \%$ da produção nacional, em 1919, para mais de $57 \%$, em 1970.

A sustentação da industrialização tardia exigiu maior consumo e investimentos internos. Para isso, o novo papel do Estado que para além da condução desenvolvimentista da política econômica no campo cambial e financeiro se constituiu cada vez mais estruturado na condução do progresso material do capitalismo. 
Gráfico 07 - Brasil: evolução da participação no valor da produção industrial por estados selecionados da federação em anos selecionados (em \%)

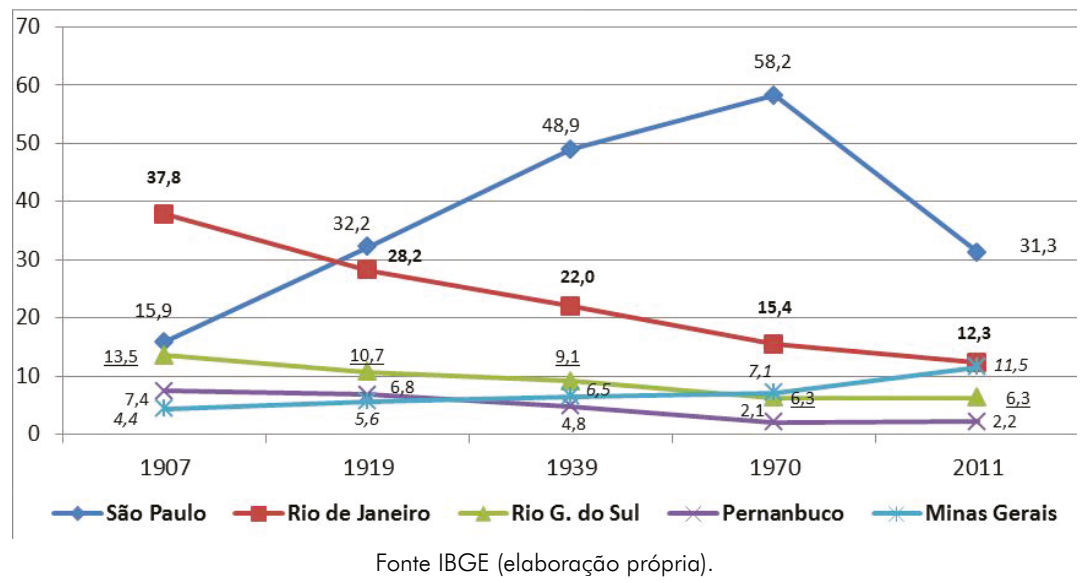

Sem maiores apoios dos capitais privados nacional e estrangeiro, coube ao Estado mobilizar recursos em prol do avanço da estrutura produtiva, sobretudo nas indústrias de base. Isso ocorreu na siderurgia (Cia. Siderúrgica Nacional - CSN), na mineração (Cia. Vale do Rio Doce - CVRD), na química (Cia. Nacional de Álcalis - CNA), na energia (Cia. Hidroelétrica do São Francisco - CHESF), na aviação e automobilística (Fábrica Nacional de Motores - FNM), nos transportes com a nacionalização das empresas de navegação e ferrovias, entre outros.

Este movimento de constituição das políticas nacionais verificado pela primeira vez no Brasil não se mostrou internacionalmente um fato isolado. Seu ineditismo a partir de 1930 decorreu da vontade nacional, a partir de uma nova maioria política antiliberal que se articulou em torno de Getúlio Vargas, frente ao liberalismo dos governos da aristocracia cafeeira, sobretudo em relação à Grande Depressão de 1929. 
Com o fim da Segunda Guerra Mundial (1939 - 1945), a posição dos Estados Unidos enquanto o novo centro dinâmico mundial foi a de seguir o Acordo de Yalta e o receituário decorrente do acordo de Bretton Woods por quase três décadas (1944 - 1973). Em geral, o reconhecimento da soberania dos países e a generalização das políticas públicas de regulação nacional dos mercados.

Para cada país, em maior ou menor grau, vigorou o funcionamento dos sistemas nacionais de políticas públicas para diversas áreas, tais como educação, saúde, transporte, trabalho, entre outras. A existência das regras de estabilidade do dólar em paridade com o ouro, ademais de juros internacionais fixos, geralmente abaixo da inflação, e da ação favorável de agências multilaterais, como o Banco Mundial e o Fundo Monetário Internacional, impulsionaram as políticas nacionais de industrialização em alguns países.

A prioridade na reconstrução do segundo pós-guerra da Europa, bem como do Japão, levou os Estados Unidos a conceber o Plano Marshall de assistência técnica e econômica ao conjunto de 16 países no valor de 13 bilhões de dólares entre 1948 e 1951 (U\$142 bi em valores de 2010). Ademais de oferecer anteparo econômico e militar ao crescimento da União das Repúblicas Socialistas Soviéticas, a reconstrução europeia se deu concomitante com o processo de internacionalização da grande empresa estadunidense, uma vez que o Plano Marshall exigia como requisitos para concretizar o repasse dos recursos, a ausência de partido comunista nos governos e a presença de firmas norte-americanas no país.

Na década de 1950, a reconstrução europeia havia sido acompanhada pelo aprofundamento da competição intercapitalista entre empresas europeias e estadunidenses. Na tentativa de elevar a capacidade competitiva, as grandes empresas europeias estabeleceram estratégia própria de 
internacionalização, buscando em outros países, como na América Latina, a oportunidade de estabelecer suas filiais (TEIXERIA, 1983).

Concomitantemente com este movimento de acirramento da competição capitalista que o Brasil aproveitou a oportunidade para dar um salto da restringida industrialização para a fase pesada realizada entre os anos de 1955 e 1980. Para tanto, dois grandes blocos de investimentos foram realizados: o Plano de Metas (1956 - 1960) e o II Plano Nacional de Desenvolvimento (1975 - 1979).

Até então, as tentativas fundamentadas no capitalismo de Estado pelo segundo governo Vargas (1951 - 1954) mostraram ser suficientes para consolidar o grande boco de investimentos associado ao desenvolvimento das indústrias de base, por meio das companhias Siderúrgica Nacional e Álcalis, da Usina Hidrelétrica de Paulo Afonso, da Petrobrás, do BNDE, entre outras. Mas com o Plano de Metas durante o governo Juscelino Kubitschek, o grande salto a um só golpe teve o êxito, proporcionado, em grande medida, pelos consideráveis Investimentos Diretos Externos que acompanharam o ingresso inicial das empresas multinacionais europeias e, posteriormente, as estadunidenses em vários ramos industriais.

Para isso, a governo JK reservou 2/3 do orçamento do Plano de Metas para expansão dos setores de energia e transportes, enquanto base para o desenvolvimento industrial. O abandono da condição de industrialização restringida se deu pela instalação do setor de bens de produção que cresceu quase seis vezes mais que a indústria de bens de consumo nos anos de 1950 (LESSA, 1983; FONSECA; MONTEIRO, 2005).

Com a difusão acelerada da indústria de bens de produção, os setores que mais se expandiram foram os da metalurgia e siderurgia, da química e fármacos, construção naval e automobilística, entre outros. A modificação estrutural na industrialização tardia brasileira 
se deu concebida pela articulação de uma trilateral capitalista, capaz de combinar as ações do Estado com os capitais do setor privado nacional e estrangeiro.

Dessa forma, a internacionalização da economia brasileira teve escala jamais vista, com sua presença, sobretudo nos setores mais dinâmicos e de maior investimento tecnológico. Mesmo assim, o ciclo de crescimento endógeno propiciado pelo avanço dos setores de bens de produção e de consumo durável explicitou a determinação das forças políticas voltadas às transformações substanciais das bases materiais do capitalismo brasileiro, com forte ênfase no planejamento estatal (TAVARES, 1975; BIELCHOWSKY, 2005).

Na sequência, o II Plano Nacional de Desenvolvimento (II PND) evidenciou o terceiro grande bloco de investimentos que contribuiu para consolidar a fase pesada da industrialização tardia. A presença de enorme liquidez internacional gerada pela ampliação do excedente comercial em dólares dos países da Organização dos Países Exportadores de Petróleo (OPEP) originada pela elevação dos preços do petróleo na década de 1970 se mostrou funcional às opções industrializantes do regime militar, sem precisar reformular o sistema financeiro nacional.

Com base nos depósitos em petrodólares, o sistema financeiro internacional disponibilizou recursos a custos irrisórios aos empréstimos externos. Para financiar o II PND, o Brasil aceitou se endividar no exterior quando as regras do Acordo de Bretton Woods haviam sido abandonadas em 1973 pelo presidente Richard Nixon dos Estados Unidos (1969 - 1974) que tornou o dólar uma moeda comum, sem mais equivalência e conversibilidade ao ouro.

Ao mesmo tempo, o II PND representou uma saída pelo crescimento econômico diante do primeiro choque do petróleo em 1973 e que havia levado a grande parte dos países a adotar uma política 
recessiva. No Brasil, ao contrário, o salto nos investimentos permitiu diminuir a dependência do petróleo, com o aumento da exploração e refino do petróleo no interior do País e geração das novas fontes de energia nuclear e etanol.

Além disso, os investimentos em substituição de importações, com a expansão da produção de bens de capital e de insumos básicos, possibilitaram ao país dominar o ciclo da industrialização tardia. Essa importante construção política nacional pela industrialização tardia elevou a economia brasileira ao patamar superior, porém insuficiente para superar a totalidade dos constrangimentos ao qual o país se encontrava situado meio século antes (LESSA, 1978; CASTRO; SOUZA, 1985; VELLOSO, 1998).

Gráfico 08 - Brasil - evolução da composição das importações em anos selecionados (em \%)

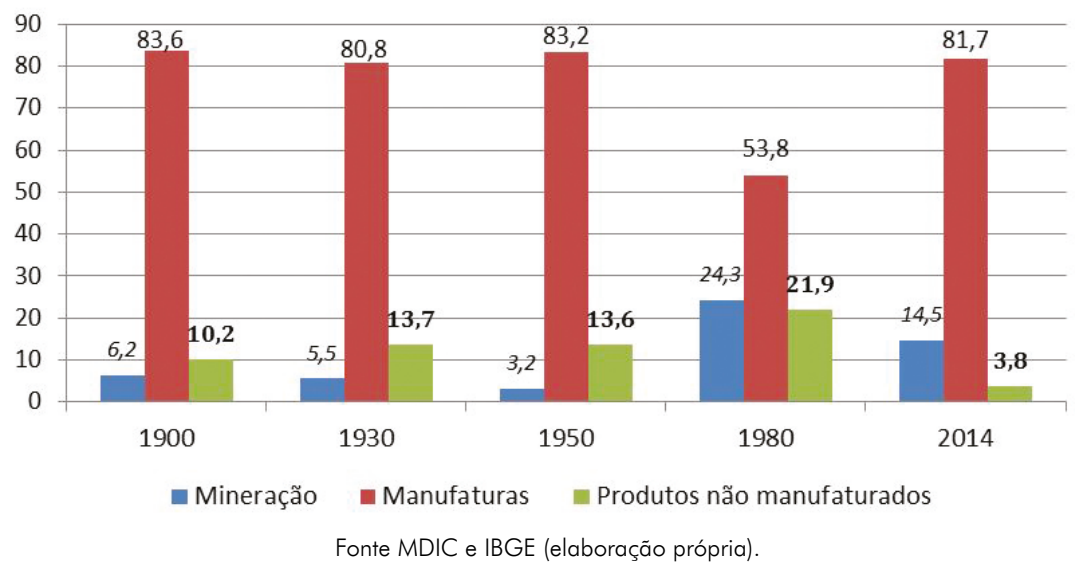

A dependência da importação de produtos manufaturados decresceu substancialmente entre as décadas de 1950 e 1980. Com os investimentos decorrentes das empresas estatais como da Eletrobrás, Petrobrás, Siderbrás, Embratel e outras, o salto no crescimento na 
produção de manufaturados foi considerável, especialmente nas indústrias de bens de produção, bens intermediários e de consumo durável.

Dessa forma, a composição dos importados alterou-se significativamente, com a perda da participação relativa de bens manufaturados. Ao mesmo tempo, a expansão das exportações, que a partir de 1979 passou a registrar maior presença relativa dos produtos manufaturados do que de produtos primários. Nos anos de 1980, a participação da manufatura atingiu a metade de toda a pauta de exportação do país, enquanto na década de 1960 representava apenas $10 \%$.

\section{Desindustrialização e semiestagnação (pós 1980)}

A inflexão assumida pela economia brasileira a partir da década de 1980 resultou na trajetória de semiestgnação da renda nacional por habitante, enquanto subproduto do movimento maior da desindustrialização. Em 35 anos de evolução da economia nacional, o PIB por habitante variou apenas 0,8\% como média anual entre 1981 e 2015.

No período imediatamente anterior (1946 - 1980), o crescimento médio anual do Produto Interno Bruto per capita foi de $3,8 \%$, sendo 2,2 vezes superior ao verificado no período de 1911 e 1945 e 38 vezes maior ao dos anos de 1876 e 1910. Se nos anos do ciclo da industrialização tardia a economia nacional dobrou de dimensão a cada decênio, a partir dos anos de 1980, com a desindustrialização, a economia passou a demorar três decênios para dobrar de tamanho.

Esta desastrada experiência em curso da desindustrialização brasileira transcorreu simultaneamente à nova configuração do capitalismo mundial. O elemento de ordem internacional que contribuiu 
decididamente para isso foi a mudança no padrão de exercício da hegemonia pelos Estados Unidos, após o abandono do acordo de Bretton Woods e o fim da Guerra Fria, com a desestruturação da União das Repúblicas Socialistas Soviéticas (URSS) enquanto alternativa ao desenvolvimento capitalista.

Gráfico 09 - Brasil: evolução média anual do Produto Interno Bruto (PIB) e do Produto Interno Bruto por habitante (PIB per capita) em períodos selecionados (em \%)

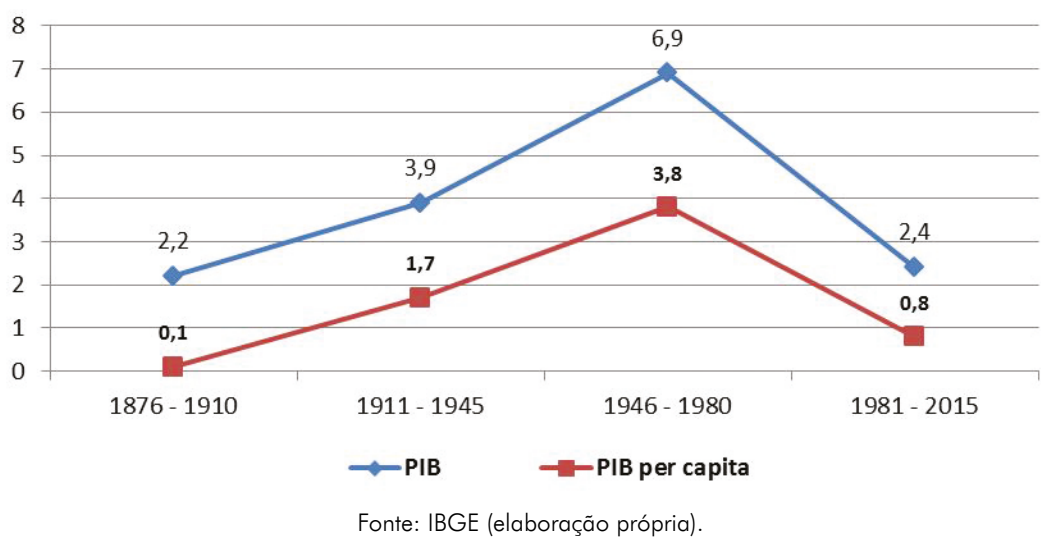

O desaparecimento do bloco soviético concedeu liberdade ao movimento das forças de mercado capazes de viabilizar uma nova fronteira de expansão capitalista na Europa do leste e Ásia. Sem mais a concorrência de uma possível alternativa à expansão capitalista, a força dos mercados passaram a cada vez mais subordinar o jogo da política nas economias do ocidente.

Com a política sendo exposta à irrelevância, sem força para impor aos mercados a vontade erigida das urnas, partidos de distintas filiações ideológicas convergiram em maior ou menor expressão ao neoliberalismo em ascensão a partir dos anos de 1980 . 
Não somente o Estado de bem estar social ficou comprometido, como as conquistas em termos de condições de trabalho e remuneração dos ocupados retroagiram.

O objetivo maior do pensamento econômico dominante foi o de reestabelecer as melhores condições possíveis para a lucratividade capitalista. Para isso, a queda nos custos salariais tornou-se estratégica, assim como a redução de impostos sobre os ricos, a elevação dos gastos militares em colaboração com as empresas de tecnologia de informação e comunicação na nova guerra cibernética e altas taxas de juros para compensar o menor dinamismo da economia.

Em grande medida, o neoliberalismo foi utilizado pelos Estados Unidos como resposta aos três grandes fracassos colhidos na década de 1970. Para lembrar, o descrédito inicial imposto ao dólar gerado pelo abandono do acordo de Bretton Woods, especialmente em 1973, com o fim da paridade ao ouro. Ou seja, o dólar enquanto moeda de curso internacional assumiu o comportamento de uma moeda qualquer, sem mais a equivalência em ouro.

$\mathrm{Na}$ sequência, a derrota das forças armadas estadunidenses na Guerra do Vietnam em 1975. A função de exercício da hegemonia mundial terminou sendo questionada quando o país com o maior e mais importante exército do mundo foi abatido por uma nação dividida e subdesenvolvida como o Vietnam e pela rebeldia interna gerada pelos movimentos sociais antiguerra nos Estados Unidos.

Por fim, o terceiro fracasso contabilizado pela insegurança energética estabelecida no Oriente Médio mediante a vitória da Revolução Iraniana, a invasão do Afeganistão pela URSS e o segundo choque do petróleo, todos em 1979. Sendo os Estados Unidos dependentes da importação de petróleo, os conflitos no Oriente Médio colocavam em 
risco a segurança energética. Na década de 1970, cerca de 4/5 de todo o petróleo importado pelos EUA provinham do Oriente Médio.

Os sinais de decadência da hegemonia estadunidense se pronunciavam nos anos de 1970. Uma economia em fase de estagnação e com alta inflação (estagflação), acrescentada do dólar em descrédito, assim como suas forças armadas e segurança energética, surpreendeu o mundo com uma inflexão de grande porte.

O resultado perseguido foi uma nova configuração do capitalismo. De imediato, a vitória eleitoral de Ronald Reagan em 1980 nos EUA permitiu liderar uma frente política internacional que trocou o receituário econômico keynesiano pelo credo neoliberal, conjuntamente com Margaret Thatcher na Inglaterra e Helmut Kohl na Alemanha.

Para isso, o programa de recuperação da hegemonia estadunidense ocorreu em três linhas distintas, porém articuladas entre si. A primeira em termos de mudança radical nas forças armadas, com e emergência da estratégia da guerra cibernética conduzida pela ascensão dos falcões militares.

A captura de parte crescente do orçamento para despesas militares se confundiu com o apoio aos investimentos nas tecnologias de informação e comunicação para as embrionárias empresas pontocom do Vale do Silício. Por meio do projeto Guerra nas Estrelas, a partir de 1983, a Guerra Fria ganhou novo impulso e praticamente foi responsável pelo esgotamento da URSS, em 1991.

Com isso, a vitoriosa estratégia militar estadunidense foi sendo transposta para a economia, cujo uso comercial e financeiro da internet e demais inovações tecnológicas resultaram em nova fronteira de expansão da rentabilidade no capitalismo digital. As formas iniciais de organização da produção das tecnologias de informação e 
comunicação logo se transformaram em corporações transnacionais que monopolizaram a partir dos EUA a oferta dos serviços e operavam em concomitância com o Departamento de Estado do mesmo país.

A segunda modificação ocorreu em relação à política externa estadunidense, cada vez mais concentrada nas operações junto ao Oriente Médio em função do risco crescente de insegurança energética. Para atender aos interesses mais imediatos das petroleiras, as forças militar e diplomática não apenas se reorganizaram como reduziram a presença e atenção em outras regiões, especialmente a partir da década de 1990, com a queda da URSS e reformas liberalizantes na Europa do leste e na Ásia.

Os conflitos variados e concentrados no Oriente Médio desviou o interesse estadunidense de alternativas ao petróleo, somente intensificado nos anos 2000 com o gás de xisto. Ademais, regiões como na América Latina e, sobretudo na Ásia, por exemplo, ganharam alguns graus de liberdade, o que permitiu acolher parcela crescente dos investimentos estrangeiros e recepcionar o deslocamento da manufatura do ocidente.

A China, em especial, expandiu sua economia aos saltos após os anos de 1990 com reformas anteriormente eficazes na atração de investimentos capazes de viabilizar extraordinariamente uma nova fronteira territorial de expansão capitalista. As maiores empresas estadunidenses, em conjunto com as de outros países, deslocaram parcela significativa do seu parque produtivo cada vez mais na forma de grandes corporações transnacionais.

Ao concentrarem o controle da produção de conteúdo monopolista, as grandes corporações transnacionais passaram a utilizar as novas tecnologias de informação e comunicação e a 
operarem em redes fragmentadas de produção e distribuição. Mais conhecidas como cadeias globais de valor.

Por fim, a terceira modificação na configuração do capitalismo mundial assentada no acúmulo do poder dos mercados financeiros. Logo no início do governo de Ronald Reagan, a adoção de medidas monetaristas de forte elevação na taxa de juros e das políticas de oferta e de desregulamentação na economia produziu um novo ciclo de financeirização capitalista.

O objetivo maior era o de recuperar a lucratividade nas atividades econômicas para promover o dinamismo empresarial. A liberalização dos lucros exigiria pelo diagnóstico neoliberal a diminuição dos custos do trabalho, bem como a redução dos tributos sobre as empresas e seus proprietários.

Ao mesmo tempo, a oferta de aplicações financeiras com retornos bem acima da inflação compensaria o baixo dinamismo capitalista vigente na década de 1970. Da mesma forma, a mudança no papel do Estado permitiria conter gastos sociais necessários para compensar as demandas maiores das despesas militares e com pagamento de juros do endividamento (BRAGA; CINTRA, 2004; BELLUZZO, 1999; MEDEIROS, 2001; FIORI, 2004; COMPARATO, 2013).

Com isso, a condução da política monetária dos EUA ganhou muito maior importância do que durante a vigência do acordo de Bretton Woods, cada vez mais reduzindo graus de liberdade nas políticas econômicas dos demais países, ao mesmo tempo em que o processo de monopolização da produção e distribuição por meio das corporações transnacionais comprimiu parcela da soberania das políticas nacionais.

Neste contexto internacional de reconfiguração do capitalismo mundial que se encaixou a movimento de desindustrialização brasileira. 
Com o governo de Ronald Reagan ampliando a taxa de juros para financiar os déficits comercial e do setor público estadunidense ocorreu o estrangulamento do padrão de financiamento dos investimentos produtivos em vários países do mundo, sobretudo do Brasil.

Acontece que parcela importante dos investimentos do II Plano Nacional de Desenvolvimento na segunda metade da década de 1970 havia sido financiada com endividamento externo. A subida na taxa de juros tornou cada vez mais elevada o custo de administração do endividamento externo, especialmente pelo fato de o governo brasileiro sacar créditos de curto prazo para atender os pagamentos com dívida de longo prazo.

Entre 1973 e 1982, por exemplo, a dívida externa dos países não produtores de petróleo aumentou 400 bilhões de dólares, sendo a metade devida às necessidades de pagamento decorrentes do aumento do preço do petróleo em 1973 e 1979. Além disso, 35\% do acréscimo do débito externo (US $\$ 140$ bilhões) resultaram da deterioração dos termos de troca provocada pela recessão global induzida pela elevação da taxa de juros estadunidense no início da década de 1980 (CLINE, 1983; LIPIETZ, 1988).

Somente o grupo do Brasil, México e Venezuela somavam, por exemplo, o montante do endividamento equivalente à época a $1 / 3$ do total da dívida externa operada por mais de 1,1 mil bancos. Diante do esgotamento do padrão de financiamento, explodiu a crise da dívida externa entre 1981 e 1983 e desencadeou operação dos EUA em coordenação com Fundo Monetário Internacional (FMI) e Banco Mundial (BM) para salvar os principais bancos credores.

De um lado, os Estados Unidos injetaram 40 bilhões de dólares no Euromercado e conduziram a desaceleração de sua taxa de juros, 
enquanto de outro, o FMI operou o programa de ajuste exportador aos países endividados enquanto gerador de renda externa capaz de pagar os serviços do endividamento. Para isso, o FMI liberou antecipadamente linhas de crédito para impedir a moratória da dívida externa mediante o atendimento de cartas de compromisso que orientaram em cada país a política econômica.

O choque da dívida externa atingiu o ciclo de industrialização tardia no Brasil. A política econômica dos anos de 1970 de fortalecimento do mercado interno foi abandonada em função do programa de ajuste exportador, que levou a economia nacional à sua primeira recessão desde 1930, com efeitos perturbadores nos macro preços.

O resultado imediato foi o fechamento generalizado da economia para o mundo, sobretudo às inovações da Terceira Revolução Tecnológica, com desorganização das finanças públicas e acelerado processo de hiperinflação. A semiestagnação do PIB per capita e o congelamento da industrialização conviveram com o derrame de recursos internos para o exterior na forma de pagamento dos serviços da dívida externa.

$\mathrm{Na}$ década de 1990, a economia nacional sofreu uma segunda mudança significativa de orientação na política econômica, com o ingresso passivo e subordinado à globalização. Do fechamento imposto pelo FMI nos anos de 1980, o país transitou rapidamente para o neoliberalismo que desregulamentou o comércio externo, as atividades produtivas e o mercado financeiro.

Nas duas faces da globalização atual, o Brasil avançou muito mais na financeira do que comercial. O comércio externo que representava em média 15,3\% do PIB na década de 1980 saltou para 21,1\% na década de 2000 , com aumento de $379 \%$ no período em consideração. 
No caso da relação entre os ativos financeiros e PIB, percebe-se o crescimento significativo de $11,8 \%$ em média na década de 1980 para $52,4 \%$ na década de 2000 . Por conta disso que os ativos financeiros que representavam $21,1 \%$ do comércio externo saltaram para $67,8 \%$ no mesmo período de tempo.

A centralidade da estabilidade monetária estabelecida após a grave crise de superinflação, entre os anos de 1979 e 1994, talvez possa ter enviesada para ter favorecido o ingresso mais financeiro que comercial do Brasil na globalização após a década de 1980. Em nome do programa de combate à inflação, como o Plano Real a partir de 1994, por exemplo, o país terminou desconstruindo o papel anterior do Estado desenvolvimentista, privatizando sem estratégia parte significativa do setor produtivo estatal (empresas e bancos) e abrindo sua economia à internacionalização produtiva e financeira.

Gráfico 10 - Brasil: evolução da média dos pesos relativos do Comércio Externo (exportações mais importações) no Produto Interno Bruto (PIB), dos Ativos Financeiros no PIB e dos Ativos Financeiros no Comércio Externo (em \%)

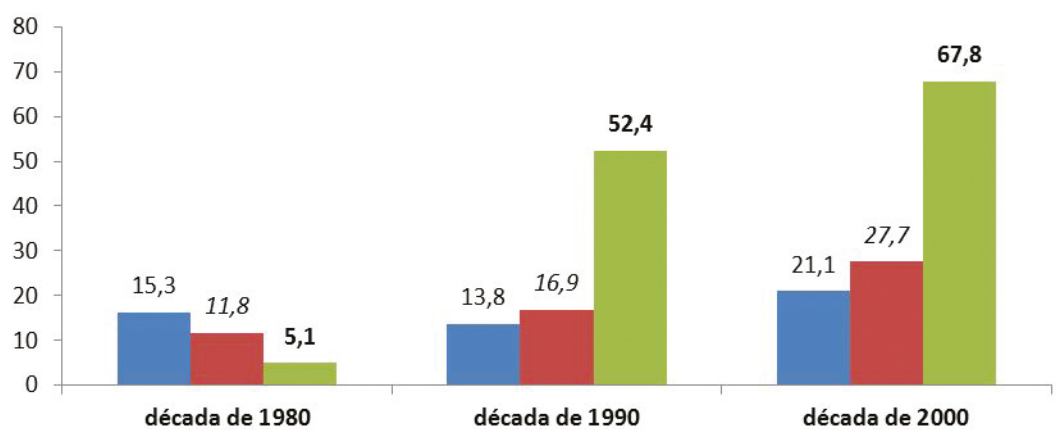

a Comércio Externo/PIB Ativos Finaceiros/PIB Ativos Financeiros/Comércio Externo Fonte: IBGE, BACEN e BIS (elaboração própria). 
Mesmo assim, acentuaram-se os déficits no setor público e na balança comercial. Tudo isso contribui de forma mais intensa para a dependência relacionada à elevada taxa de juros reais para atração de recursos externos necessários para o fechamento do balanço de pagamentos.

O ingresso de dólares se intensificou no Brasil desde os anos de 1990, após uma década de restrição ao acesso a recursos externos. Mas para isso o país praticou taxas de juros entre as mais altas do mundo, convivendo por muito tempo e de forma prejudicial ao setor produtivo com moeda nacional supervalorizada.

Nestas circunstâncias que a desindustrialização se fortaleceu, pois as condições internas ao avanço da produção de manufatura tornaram-se insustentáveis. Paralelamente, as elevadas taxas de juros fomentaram cada vez mais o processo de financeirização de riqueza, o que levou à subordinação do capital industrial às demais frações da classe dominante.

Desde a década de 1980 que a força da desindustrialização expressa o encapsulamento do capital industrial à lógica financeira, cujos efeitos resultam na perda relativa da manufatura na produção do país. Também tem importância no comportamento da produção industrial, as alterações na composição do valor da transformação da manufatura.

O principal aspecto a ser destacado se deve a deterioração do setor industrial produtor de bens de capital, que reduziu em $1 / 3$ entre os anos de 1980 e 2013, após significativo crescimento nos períodos anteriores. Para os mesmos anos, o peso relativo da indústria de bens de consumo aumentou levemente, depois da trajetória anterior de queda, enquanto o setor produtor de bens intermediários estancou a sua participação relativa. 
Tudo isso, é claro, numa indústria que passou a representar menos de $10 \%$ do PIB nacional na segunda década do século XXI, enquanto nos anos de 1980 respondia por mais de 1/3 da economia brasileira. Mesmo após algumas tentativas governamentais de reanimar o tecido industrial desde os anos 2000, o sentido da desindustrialização não foi interrompido.

Gráfico 11 - Brasil: evolução da composição do valor da transformação industrial segundo as categorias de uso (total $=100 \%$ )

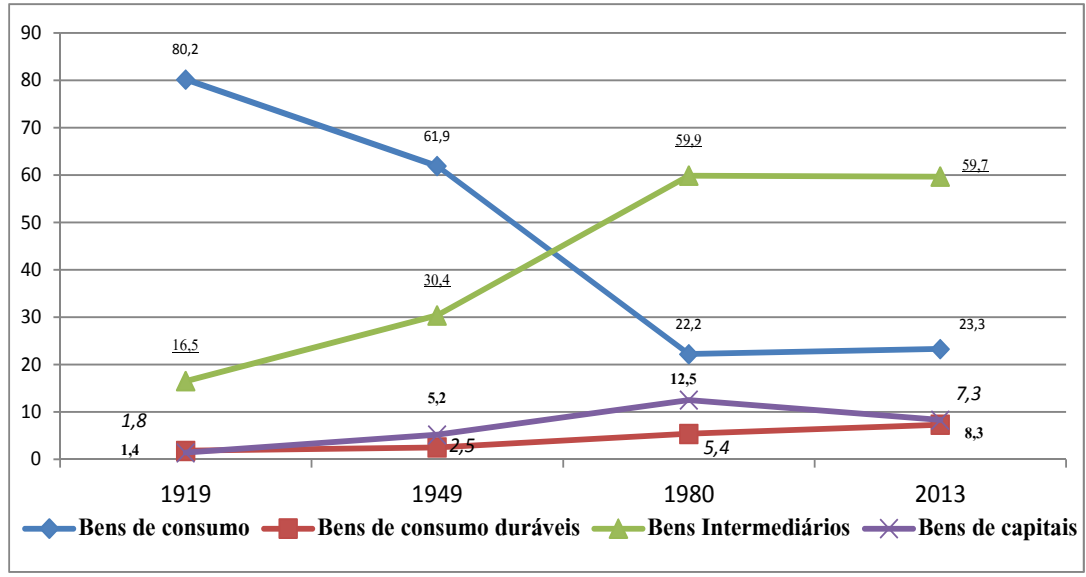

Fonte: IBGE (elaboração própria).

A prevalência da combinação de altos juros reais com valorização cambial se mostrou improdutiva para produção industrial. Sem a retomada dos investimentos, a possibilidade do crescimento foi contida pela ocupação da capacidade ociosa e o transbordamento da elevação da renda interna para a ampliação das importações, sobretudo de produtos manufaturados e de maior valor tecnológico.

Quando parecia reunir as condições para o estabelecimento de um quarto bloco de investimentos a partir do Plano de Aceleração do 
Crescimento, em 2006, a emergência da crise de dimensão global iniciada em 2008 tornou o esforço governamental de então em políticas anticíclicas. O objetivo foi o de evitar a internalização da crise externa e o seu aprofundamento maior na economia brasileira.

O êxito, neste sentido, foi inegável, ainda que não tenha sido suficiente para evitar a continuidade do quadro geral da desindustrialização. Da mesma forma, a sequência da semiestagnação da renda per capita no Brasil.

Concomitante com o esvaziamento do tecido industrial constatou-se também o enfraquecimento dos empresários industriais, bem como de suas instituições representativas, outrora de importância inegável na determinação das agendas governamentais. Seus movimentos de natureza política eram, até então, destacados na orientação da classe dominante.

No período recente, a burguesia industrial perdeu dinamismo e centralidade na agenda política no interior da sociedade. O seu papel subordinado no interior das frações do capitalismo indica a força da desindustrialização.

De certa forma, percebe-se certa transição de industriais a comerciantes importadores de manufatura. Não por acaso que a presença mais recente de cerca de $80 \%$ da pauta de importação brasileira constituída por bens industriais enuncia a debilidade competitiva da estrutura produtiva internalizada no país.

Assim como a região Sudeste, em especial o estado de São Paulo, incorporou no passado a centralidade e força da industrialização tardia, apresentam no período atual os sinais de decadência relativa da produção de manufatura. No final da década de 1970, quando a indústria representava mais de $1 / 5$ do PIB nacional, somente São Paulo respondia por quase $2 / 3$ da indústria do país. 
Na segunda década do século XXI, a indústria passou a responder por menos de $10 \%$ do PIB e o peso relativo de São Paulo na produção de manufatura brasileira decaiu para menos de $1 / 3$. Resumidamente, o valor da produção industrial paulista diminuiu de $18 \%$ do PIB nacional nos anos de 1980 para apenas 3\% nos anos 2010.

\section{Considerações gerais}

A constituição, o desenvolvimento e a crise recente da industrialização fundamentam as especificidades do capitalismo no Brasil. As condicionalidades da montagem de uma industrialização tardia não se apresentaram simples, exigindo esforço significativo do conjunto de sua população, que nem sempre conseguiu absorver parcela compatível dos frutos do progresso econômico.

Com a mudança no cenário internacional a partir da década de 1970 o comportamento da economia brasileira foi fortemente atingido desde então. A fase recente explicita, guardada a devida proporção, a alteração brusca no contexto externo durante a década de 1930 e que terminou por estrangular o ciclo econômico e político anterior.

Naquela oportunidade, não apenas a experiência da República Velha (1889 - 1930) se extinguiu como esgotou o sucesso da antiga economia capitalista primário exportadora. A formação de uma nova maioria iniciada pelo governo de Getúlio Vargas descortinou um novo e desconhecido horizonte de meio século de transformações consideráveis nas estruturas social, econômica e política, protagonizada pela burguesia industrial e com o apoio decisivo do Estado desenvolvimentista.

O conservadorismo político mediado pela presença predominante do autoritarismo impossibilitou a realização de reformas civilizatórias 
do capitalismo. Sem as reformas fundiária, tributária e social, o progresso econômico representado pelo avanço considerável da industrialização permaneceu fundamentalmente concentrado em segmentos privilegiados da população.

Nos últimos 35 anos, contudo, o ciclo político iniciado pela Nova República registrou êxito, sobretudo na sustentação do mais longevo regime democrático e na estabilidade monetária, após 21 anos de autoritarismo (1964 - 1985) e 15 anos de superinflação (1979 - 1994). Tudo isso, contudo, não se mostrou suficiente para que o país recompusesse um novo padrão de crescimento econômico.

Assiste-se à vigência da desindustrialização concomitante à consolidação da tendência de semiestagnação da renda per capita nacional. A desconstrução do Estado desenvolvimentista a partir do final da década de 1980 foi acompanhada do enfraquecimento do capital industrial.

Com a passividade do ingresso na globalização, a dominância financeira passou a prevalecer, subordinando a burguesa indústria e o aparelho do Estado, submissos às elevadas taxas reais de juros e à valorização da moeda nacional. Com o bloqueio da financeirização da riqueza no Brasil, a modernização industrial fica afastada, tornando mais distante o horizonte de superação das condições novas e velhas do subdesenvolvimento no Brasil.

Com uma média de crescimento ao redor dos $2 \%$ ao ano, o Brasil necessitou de 35 anos para dobrar a sua capacidade de produção, enquanto a China tem duplicado a cada 7 anos. Sem o retorno ao crescimento econômico motivado pela reindustrialização brasileira, o horizonte do subdesenvolvimento tende a permanecer inatacável. 